\title{
Proton Transfer Mechanisms in Bimetallic Hydrogenases
}

Hulin Tai, ${ }^{\dagger}$ Shun Hirota, ${ }^{*},+$ and Sven T. Stripp ${ }^{*, \S}$

${ }^{\dagger}$ MOE Key Laboratory of Natural Resources of the Changbai Mountain and Functional Molecules, Department of Chemistry, Yanbian University, Yanji 133002, Jilin, China

$\$$ Division of Materials Science, Graduate School of Science and Technology, Nara Institute of Science and Technology, Ikoma, Nara 630-0192, Japan

$\S$ Bioinorganic Spectroscopy, Department of Physics, Freie Universität Berlin, 14195 Berlin, Germany

\section{Corresponding Authors}

*E-mail: hirota@ms.naist.jp

*E-mail: sven.stripp@fu-berlin.de

\section{Keywords}

hydrogen, biocatalysis, hydride chemistry, photochemistry, infrared spectroscopy 
Contents

CONSPECTUS

1. INTRODUCTION

2. PROTON TRANSFER IN [NIFE]-HYDROGENASE 9

$\begin{array}{ll}\text { 2.1 Light sensitivity of the } \mathrm{Ni}-\mathrm{Fe} \text { active site } & 9\end{array}$

2.2 Proton transfer during the catalytic cycle $\quad 11$

2.3 Understanding [NiFe]-hydrogenase catalysis 14

$\begin{array}{ll}2.4 \text { Alternative proton transfer pathways } & 17\end{array}$

3. PROTON TRANSFER IN [FEFE]-HYDROGENASE 18

$\begin{array}{ll}\text { 3.1 Light sensitivity of the Fe-Fe active site } & 18\end{array}$

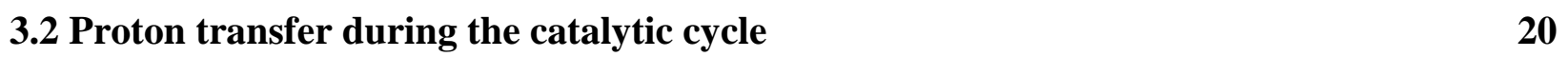

3.3 Understanding [FeFe]-hydrogenase catalysis $\quad 24$

$\begin{array}{ll}3.4 \text { Alternative proton transfer pathways } & 25\end{array}$

4. PROTON TRANSFER IN BIMETALLIC HYDROGENASE 26

5. ACKNOWLEDGEMENTS 27

$\begin{array}{lr}\text { 6. REFERENCES } & 27\end{array}$ 


\section{Conspectus}

Hydrogenases are iron-sulfur enzymes that catalyze proton reduction and $\mathrm{H}_{2}$ oxidation with outstanding efficiency. They are considered blueprints for the design of transition metal complexes, e.g. as heterogenous catalysts in the context of $\mathrm{H}_{2}$ production from water. Moreover, hydrogenases are biological model systems for metal hydride chemistry and proton-coupled electron transfer.

Depending on the composition of the active site cofactor, [NiFe]-hydrogenases are distinguished from [FeFe]-hydrogenases. The former binds a hetero bimetallic nickel/iron site, embedded in the protein by four cysteine ligands. The later, by contrast, carries a homo bimetallic iron/iron site attached to the protein by only a single cysteine. Carbon monoxide and cyanide ligands $(\mathrm{CO} / \mathrm{CN})$ at the active site facilitated detailed investigations of hydrogenase catalysis by infrared spectroscopy, owing to strong signals and redox-dependent frequency shifts. However, the details of proton transfer have not been addressed experimentally.

We found that specific redox state transitions in [NiFe]- and [FeFe]-hydrogenase can be triggered by visible light to record extremely sensitive 'light-minus-dark' infrared difference spectra monitoring key amino acid residues as shown in the ToC figure. As these transitions are coupled to protonation changes, our data allowed investigating dynamic hydrogen-bonding changes that go well beyond the resolution of protein crystallography.

In $[\mathrm{NiFe}]$-hydrogenase, photolysis of the bridging hydride ligand in the 'Ni-C' state was followed by rapid accumulation of the 'Ni-SI ${ }_{a}$ ' state and/or ' $\mathrm{Ni}-\mathrm{L}$ ' state. Infrared difference spectra in various isotopic media clearly indicated the formation of a protonated cysteine residue as well as hydrogen-bonding changes involving the $\mathrm{COOH}$ group of a glutamic acid residue and a 'dangling water' molecule. These findings are in excellent agreement with crystallographic analyses of $[\mathrm{NiFe}]$-hydrogenase in the $\mathrm{Ni}-\mathrm{R}$ state and allowed devising a molecular precise model of catalytic proton transfer.

In [FeFe]-hydrogenase, an external redox dye was used to accumulate the 'Hred' state over the oxidized resting state 'Hox'. Infrared difference spectra of wild-type enzyme and numerous amino acid variants indicated hydrogen-bonding changes involving the $\mathrm{COOH}$ groups of two glutamic 
acid residues. Moreover, we noted the deprotonation of an arginine residue. Crystallographic analyses of [FeFe]-hydrogenase in the Hox state failed to explain the rapid proton transfer due to a 'breach' in the succession of residues. To this end, our findings facilitated a molecular precise model of 'discontinued' proton transfer.

The comparison of catalytic proton transfer in bimetallic hydrogenases emphasizes the role of the outer coordination sphere. We suggest that the stable protonation of a nickel-ligating cysteine in [NiFe]-hydrogenase has a crucial influence on the preferred direction of proton flow and catalysis (i.e., $\mathrm{H}_{2}$ oxidation). On the contrary, proton transfer in $[\mathrm{FeFe}]$-hydrogenase involves an adjacent cysteine as a relay group that promotes both proton release and proton uptake. We presume that this causes the notable bidirectionality of [FeFe]-hydrogenase. These observations must guide the design of biomimetic compounds for the production or consumption of $\mathrm{H}_{2}$.

\section{Table of Contents}

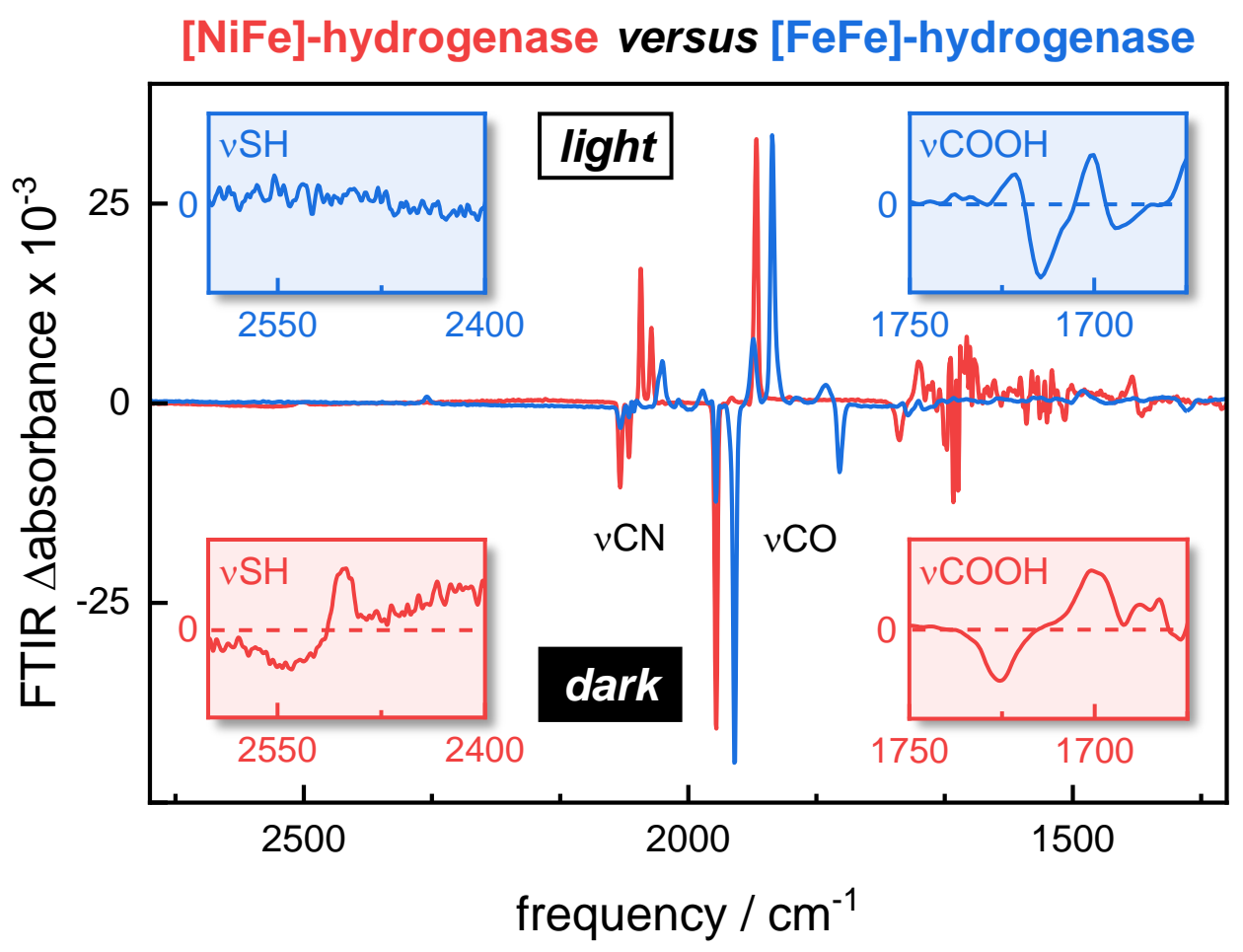




\section{Introduction}

Hydrogenases are iron-sulfur enzymes that catalyze hydrogen turnover in archaea, bacteria, and algae. Three phylogenetically independent classes have been described: [NiFe]-hydrogenase, $[\mathrm{FeFe}]-h y d r o g e n a s e$, and $[\mathrm{Fe}]-h y d r o g e n a s e .{ }^{1}$ In general, the bimetallic $[\mathrm{NiFe}]-$ and $[\mathrm{FeFe}]-$ hydrogenases show higher catalytic activities than [Fe]-hydrogenase and catalyze both $\mathrm{H}_{2}$ oxidation and proton reduction. ${ }^{1-3}$ The reaction includes a hydride intermediate (heterolytic hydrogen turnover, Eq. 1):

Eq. 1

$$
\mathrm{H}_{2} \rightleftharpoons\left[\mathrm{H}^{+}+\mathrm{H}^{-}\right] \rightleftharpoons 2 \mathrm{H}^{+}+2 \mathrm{e}^{-}
$$

The active site cofactors of bimetallic hydrogenases inspired numerous biomimetic compounds designed to cleave $\mathrm{H}_{2}$ (e.g., in electrochemical half cells) or produce $\mathrm{H}_{2}$ as a 'green fuel' ${ }^{4-6}$ But while the $\mathrm{Ni}-\mathrm{Fe}$ and $\mathrm{Fe}-\mathrm{Fe}$ cofactors have been characterized by X-ray diffractometry (XRD), electron paramagnetic resonance (EPR) spectroscopy, Fourier-transform infrared (FTIR) spectroscopy, and other techniques ${ }^{1}$, the details of proton transfer were unraveled only recently. ${ }^{7,8}$ The novel findings, collected independently in our laboratories, emphasize the importance of the 'outer' coordination sphere and the selective supply and detraction of protons.

Standard [NiFe]-hydrogenases are comprised of two subunits. ${ }^{9,10}$ The small subunit binds three iron-sulfur clusters, termed proximal, medial, and distal relative to the position of the $\mathrm{Ni}-\mathrm{Fe}$ site (Figure 1A). These clusters facilitate electron transfer between the protein surface and the active site cofactor. The $\mathrm{Ni}-\mathrm{Fe}$ site is anchored to the large subunit by four cysteine residues: two terminal ligands to the nickel ion and two bridging ligands between the nickel and iron ions (Figure 1B). ${ }^{9}$ The iron ion is further coordinated by one carbon monoxide (CO) and two cyanide $\left(\mathrm{CN}^{-}\right)$ligands and an additional ligand that may bind in the $\mathrm{Ni}-\mathrm{Fe}$ bridging position. ${ }^{1,2} \mathrm{The} \mathrm{Ni}-\mathrm{Fe}$ 
site exists in several redox states (Figure 1C): the nickel ion changes its oxidation state (i.e., $\mathrm{Ni}^{3+}$, $\mathrm{Ni}^{2+}$, and $\left.\mathrm{Ni}^{+}\right)$during the catalytic cycle whereas the low-spin iron ion retains the ferrous state $(S$ $\left.=0, \mathrm{Fe}^{2+}\right) .{ }^{2,4}$ There are several well-conserved amino acid residues close to the $\mathrm{Ni}-\mathrm{Fe}$ site (Figure 1B), which have been proposed to play important roles in the catalytic reaction of [NiFe]hydrogenase (Eq. 1). $)^{2,4,9,11}$

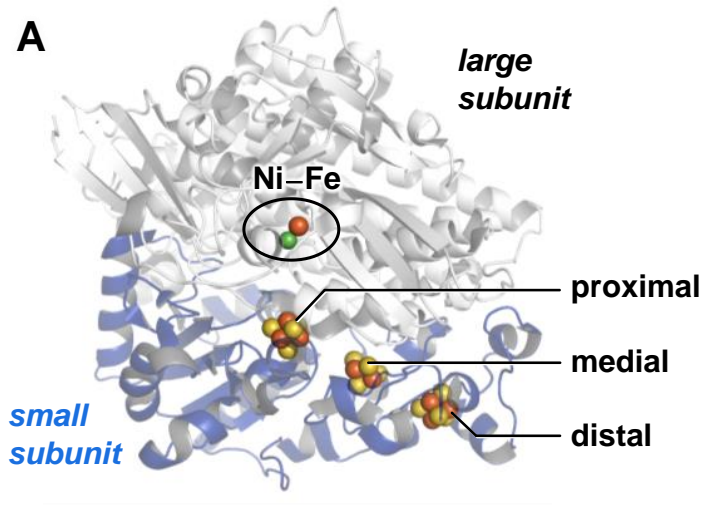

B

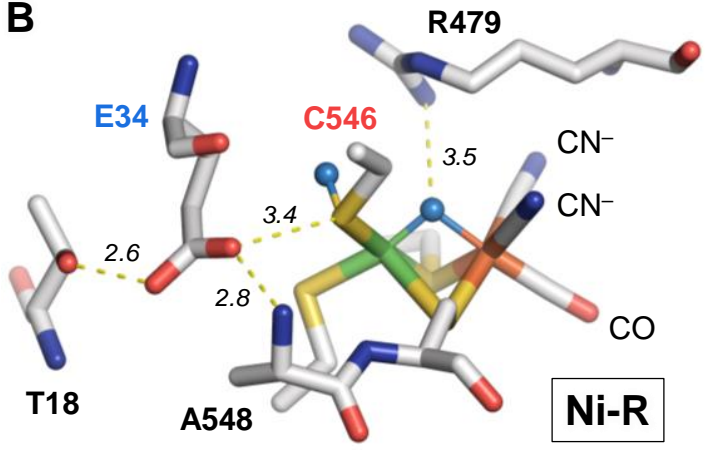

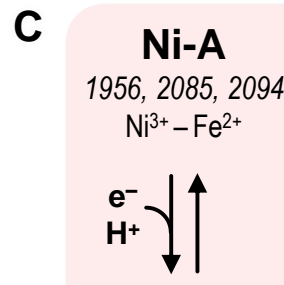

Ni-SU

1958, 2089, 2100 $\mathrm{Ni}^{2+}-\mathrm{Fe}^{2+}$

inactive

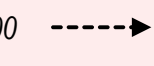

1923, 2057, 2071
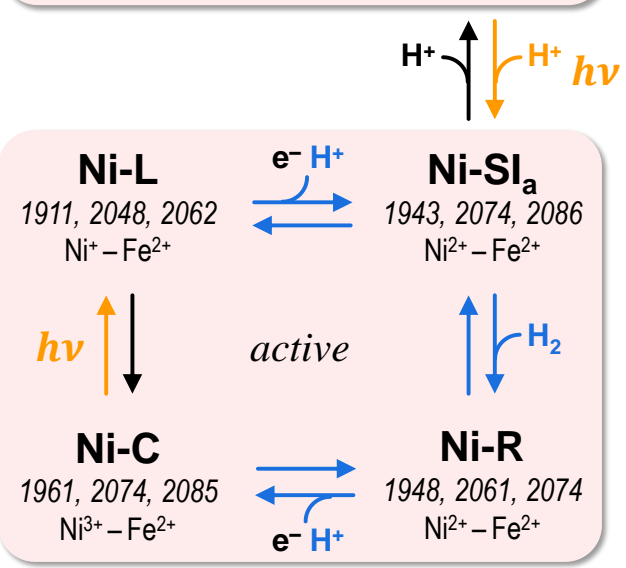

Figure 1 - [NiFe] hydrogenase. (A) X-ray crystal structure of the [NiFe]-hydrogenase from $D v \mathrm{MF}$ (pdb coordinates $4 \mathrm{U} 9 \mathrm{H}$ ). The $\mathrm{Ni}-\mathrm{Fe}$ site and the proximal, medial, and distal iron-sulfur clusters are highlighted. (B) Ni-Fe site in the Ni-R state and proton transfer pathway (distances in $\AA$ ). The $\mu \mathrm{H}^{-}$ligand and the extra proton at C546 are shown as light blue spheres. (C) Reaction scheme of $[\mathrm{NiFe}]-$ hydrogenase including the formal charges of the $\mathrm{Ni}-\mathrm{Fe}$ site. The $\mathrm{CO}$ and $\mathrm{CN}^{-}$ stretching frequencies of the $[\mathrm{NiFe}]$-hydrogenase from $D v \mathrm{MF}$ are given in $\mathrm{cm}^{-1}$. Note that the NiSIr and Ni-C states are sensitive to visible light (orange arrows). Blue arrows depict catalytic proton transfer. The dashed arrow marks a speculative transition. 
Standard [FeFe]-hydrogenases are comprised of two domains. ${ }^{12,13}$ The 'F-domain' binds up to five iron-sulfur clusters that facilitate electron transfer between the protein surface and the active site cofactor (Figure 2A). In the 'H-domain', four cysteines residues anchor the active site cofactor or 'H-cluster': three terminal ligands to a $[4 \mathrm{Fe}-4 \mathrm{~S}]$ cluster and a single bridging ligand between the [4Fe-4S] cluster and the $\mathrm{Fe}-\mathrm{Fe}$ site (Figure 2B). The latter is coordinated by up to four CO ligands, two $\mathrm{CN}^{-}$ligands, and an aminodithiolate ligand (adt) that bridges $\mathrm{Fe}_{\mathrm{p}}$ and $\mathrm{Fe}_{\mathrm{d}}$ ('p' refers to proximal and ' $d$ ' refers to distal iron ion, relative to the $[4 \mathrm{Fe}-4 \mathrm{~S}]$ cluster). ${ }^{12-14}$ The H-cluster exists in several redox states (Figure 2C): the $\mathrm{Fe}-\mathrm{Fe}$ site changes between 'super-oxidized' $\left(\mathrm{Fe}_{\mathrm{p}}{ }^{2+}-\mathrm{Fe}_{\mathrm{d}}{ }^{2+}\right)$, oxidized mixed-valence $\left(\mathrm{Fe}_{\mathrm{p}}{ }^{2+}-\mathrm{Fe}_{\mathrm{d}}{ }^{+}\right)$, and formally reduced states $\left(\mathrm{Fe}_{\mathrm{p}}^{+}-\mathrm{Fe}_{\mathrm{d}}^{+}\right)$, whereas the low-potential $[4 \mathrm{Fe}-4 \mathrm{~S}]$ cluster changes between oxidized $(+2)$ and reduced $(+1)$ states. $^{3}$ There are several well-conserved amino acid residues and water molecules that connect the $\mathrm{Fe}-\mathrm{Fe}$ site to the protein surface (Figure 2B), which have been shown to play important roles in the catalytic reaction of [FeFe]-hydrogenase (Eq. 1). ${ }^{15-17}$ 

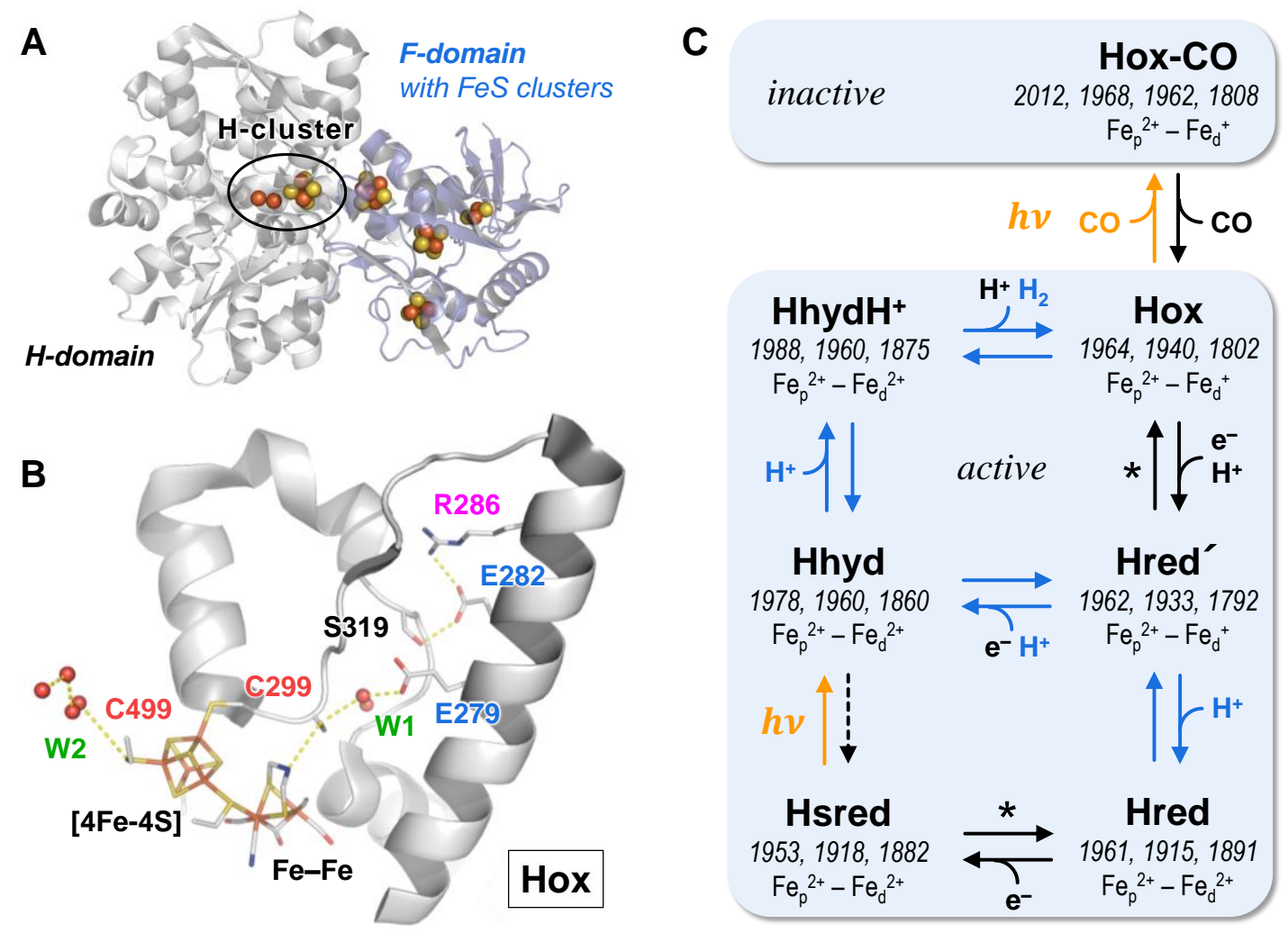

Figure 2 - [FeFe]-hydrogenase. (A) X-ray crystal structure of the $[\mathrm{FeFe}]$-hydrogenase from $C p \mathrm{I}$ (pdb coordinates 4XDC). The H-cluster and accessory iron-sulfur clusters are highlighted. (B) The $\mathrm{H}$-cluster in the Hox state and proton transfer pathway. The Fe-Fe site is connected to the protein surface by a conserved trajectory of amino acid residues and water molecules (W1). Additionally, a chain of water molecules (W2) connects the protein surface and the $[4 \mathrm{Fe}-4 \mathrm{~S}]$ cluster. (C) Reaction scheme including the formal charges of the $\mathrm{Fe}-\mathrm{Fe}$ site. The $\mathrm{CO}$ and $\mathrm{CN}^{-}$stretching frequencies of $\mathrm{CrHydA} 1$ are given in $\mathrm{cm}^{-1}$. The asterisk highlights redox/protonation changes at the $[4 \mathrm{Fe}-4 \mathrm{~S}]$ cluster. Note that the Hox and Hsred states are sensitive to visible light (orange arrows). Blue arrows depict catalytic proton transfer. The dashed arrow marks a speculative transition. 
In this account, we will review recent progress in the understanding of catalytic and regulatory proton transfer in bimetallic hydrogenases. We will discuss how proton transfer (PT) and protoncoupled electron transfer (PCET) influence the formation of key redox states in [NiFe]hydrogenase (Chapter 2) and [FeFe]-hydrogenase (Chapter 3). The high-resolution crystal structures available for bimetallic hydrogenases represent the basis on which potential PT trajectories have been discussed and simulated. ${ }^{18-21}$ Going beyond the scope of XRD, we will focus on FTIR difference spectroscopy unraveling the subtle changes when switching between different states. Infrared spectroscopy allows interrogating chemical entities involved in PT directly, e.g., cysteine, glutamic/aspartic acid, and arginine residues as well as individual $\mathrm{H}_{2} \mathrm{O}$ molecules ('dangling water'). ${ }^{22}$ Although hydrogenases do not carry a catalytic chromophore, visible light can be used to trigger protonation changes, e.g., by photolyzing bridging hydride ligands or exciting redox dyes that initiate PCET. ${ }^{7,8}$ The account will close on a discussion of similarities and differences between bimetallic hydrogenases (Chapter 4).

\section{Proton transfer in [NiFe]-hydrogenase}

\subsection{Light sensitivity of the $\mathrm{Ni}-\mathrm{Fe}$ active site}

The Ni-SIr and Ni-C states of the [NiFe]-hydrogenase from Desulfovibrio vulgaris Miyazaki F $(D v \mathrm{MF})$ converted to Ni-SIa upon laser irradiation at $514.5 \mathrm{~nm}$ under cryogenic conditions. ${ }^{23,24}$ Ni-C converted to Ni-SIa via $\mathbf{N i - L}$ when the proximal [4Fe-4S] cluster was oxidized (2+) but only to Ni-L when it was reduced $(1+) .{ }^{24}$ These photoconversions allowed obtaining 'light-minus-dark' FTIR difference spectra and facilitated investigating the PT mechanism of [NiFe]-hydrogenase. 
In the absence of $\mathrm{O}_{2}, \mathbf{N i}-\mathbf{S I}_{\mathbf{a}}$ converts to the inactive Ni-B state upon one-electron oxidation and insertion of a bridging hydroxo $\left(\mu \mathrm{OH}^{-}\right)$ligand at the $\mathrm{Ni}-\mathrm{Fe}$ site ('anaerobic inactivation'). ${ }^{2,9}$ This process includes Ni-SI $\mathbf{r}$ as a transient intermediate. The acid-base equilibrium between Ni-SI $\mathbf{~}_{\mathbf{a}}$ and Ni-SI is a common feature among [NiFe]-hydrogenases and the equilibrium exhibits a $\mathrm{p} K_{\mathrm{a}}$ value of about 8., ${ }^{1,2}$ Two models have been proposed to explain this behavior (Figure 3): In the first model, the $\mu \mathrm{OH}^{-}$ligand exists in $\mathbf{N i - S I}$ and leaves the $\mathrm{Ni}-\mathrm{Fe}$ site upon protonation as a water molecule, producing Ni-SIa. In the second model, Ni-SI $\mathbf{r}$ accepts a proton at the terminal $\mathrm{Ni}^{2+}$ coordinating cysteine side chain (C546 in $D v \mathrm{MF}$, compare Figure 1B). Recently, we have shown that C546 is deprotonated in the conversion of Ni-L to Ni-SI $\mathbf{a}$ (Chapter 2.2), which excludes the second mechanism. ${ }^{7}$

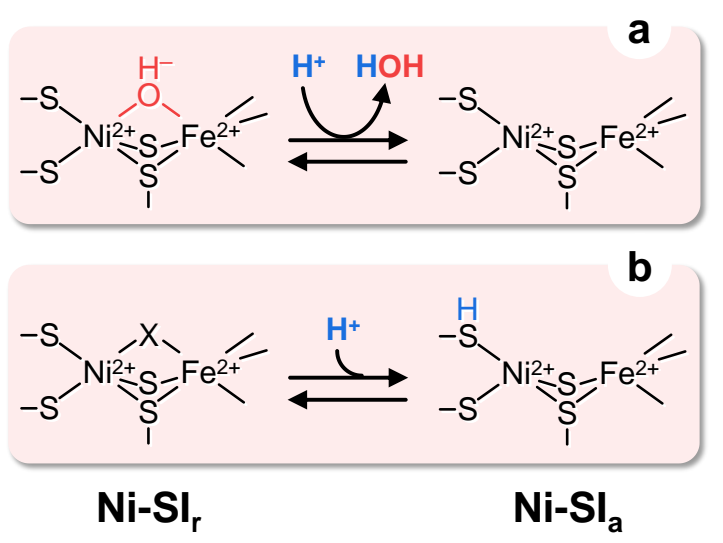

Figure 3 - Anaerobic inactivation of [NiFe]-hydrogenase. The two proposed models for the equilibrium between Ni-SIr and Ni-SIa. (a) The first model is characterized by the dissociation/association of the $\mu \mathrm{OH}^{-}$ligand. (b) The second model comprises the protonation of a coordinating cysteine. ' $\mathrm{X}$ ' may be $\mathrm{OH}^{-}, \mathrm{H}_{2} \mathrm{O}$, or empty. 
The PT dynamics for the equilibrium between Ni-SI $\mathbf{r}$ and Ni-SI $\mathbf{I}_{\mathbf{a}}$ have been identified utilizing dark adaption after irradiation of Ni-SI $\mathbf{r}$ under cryogenic conditions. ${ }^{25}$ The back reaction of Ni-SI into Ni-SI $\mathbf{r}$ in $\mathrm{H}_{2} \mathrm{O}$ and $\mathrm{D}_{2} \mathrm{O}$ was described by first-order kinetics. Moreover, a huge activation energy value $\left(E_{\mathrm{a}} \approx 65 \mathrm{~kJ} \mathrm{~mol}^{-1}\right)$ and a large kinetic isotope effect $\left(k_{\mathrm{H}} / k_{\mathrm{D}}=\sim 150\right)$ were determined, which simple $\mathrm{S}-\mathrm{H}$ bond cleavage cannot explain. ${ }^{26}$ Rather, the results indicate that the conversion of $\mathbf{N i - S l} \mathbf{a}$ to Ni-SI $\mathbf{r}$ is an intricate reaction supporting the first model, in which the conversion requires not only the transfer of a water molecule into the $\mathrm{Ni}-\mathrm{Fe}$ site but also the extraction of a proton from a water molecule (Figure 3).

\subsection{Proton transfer during the catalytic cycle}

The $\mathrm{Ni}-\mathrm{Fe}$ site adopts several oxidation states during the catalytic cycle, namely $\mathbf{N i - S I _ { \mathbf { a } }}\left(\mathrm{Ni}^{2+}\right), \mathbf{N i}-$ $\mathbf{R}\left(\mathrm{Ni}^{2+}\right)$, Ni-C $\left(\mathrm{Ni}^{3+}\right)$, and Ni-L $\left(\mathrm{Ni}^{+}\right) .{ }^{2}$ These states convert among each other by addition or release of $\mathrm{H}_{2}$, protons, and/or electrons (Figure 1C). The catalytic reaction mechanism at the $\mathrm{Ni}-\mathrm{Fe}$ site of $[\mathrm{NiFe}]-$ hydrogenase is rather well understood; however, the mechanism of catalytic PT is still under debate..$^{2,4,9,11}$

The primary proton acceptor during the catalytic oxidation of $\mathrm{H}_{2}$ has been proposed by structural ${ }^{9}$ and theoretical studies. ${ }^{19,27}$ Following this model, one proton is transferred from the $\mathrm{Ni}-\mathrm{Fe}$ site to a terminal Ni-coordinating cysteine (i.e., C546 in $D v \mathrm{MF}$ ), which may act as the entry point of the PT pathway. ${ }^{9,19}$ Mutagenesis studies have shown that a conserved glutamic acid residue (i.e., E34 in $D v \mathrm{MF}$ ) located close to $\mathrm{C} 546$ is also important for the PT during the catalytic reaction. ${ }^{28-31}$ For example, variation of $\mathrm{E} 25$ to glutamine in the [NiFe]-hydrogenase from Desulfovibrio fructosovorans (eq. E34 in $D v \mathrm{MF}$ ) resulted in a decrease of $\mathrm{H}_{2}$ oxidation activity to less than $0.1 \% .{ }^{28}$ Greene et al. showed by time-resolved IR spectroscopic studies that $\mathrm{E} 17$ in the $\mathrm{O}_{2}$-tolerant 
[NiFe]-hydrogenase from Pyrococcus furiosus (eq. E34 in $D v \mathrm{MF}$ ) is a proton donor/acceptor for the interconversion between $\mathbf{N i}-\mathbf{C}$ and $\mathbf{N i}-\mathbf{S I}_{\mathbf{a}}{ }^{29}$

We have reported the first spectroscopic evidence for the changes in the protonation state of the C546 ligand and the E34 side chain near the $\mathrm{Ni}-\mathrm{Fe}$ site of $D v \mathrm{MF}[\mathrm{NiFe}]$-hydrogenase. ${ }^{7} \mathrm{We}$ recorded cryogenic FTIR difference spectra by utilizing the light-induced conversion of Ni-C (negative bands) into Ni-L (positive bands). Positive SH and SD stretching bands were observed at 2505 and $1822 \mathrm{~cm}^{-1}$ (Figure 4, spectra a/b), respectively, and could be assigned to C546 of NiL. ${ }^{7}$ Similar frequencies for metal-coordinated thiols have been observed in $\mathrm{Ni}-\mathrm{Fe}$ and $\mathrm{Fe}-\mathrm{Fe}$ model compounds. ${ }^{32,33}$ Moreover, computational studies have shown that C546 is most easily protonated among all the cysteine ligands, resulting in stabilization of $-32.5 \mathrm{~kJ} \mathrm{~mol}^{-1}$ in Ni-L. ${ }^{27}$ Interestingly, no SH stretching band was observed for Ni-C and Ni-SI $\mathbf{a}$, indicating that the C546 is deprotonated in these states. ${ }^{7}$ Temperature-dependent FTIR studies on the equilibrium between C546-SH and C546-S $\mathrm{S}^{-}$in Ni-L suggest $\Delta \mathrm{H}$ and $\Delta \mathrm{S}$ values of $6.4 \pm 0.8 \mathrm{~kJ} \mathrm{~mol}^{-1}$ and $25.5 \pm 10.3 \mathrm{~J}$ $\mathrm{mol}^{-1} \mathrm{~K}^{-1}$, which indicates efficient PT at the $\mathrm{Ni}-\mathrm{Fe}$ site. ${ }^{34}$ In sum, these results strongly support the hypothesis that the sulphur atom of C546 is a proton acceptor/donor for the conversion of NiC to Ni-SIa via Ni-L in $D v \mathrm{MF}[\mathrm{NiFe}]$-hydrogenase. 


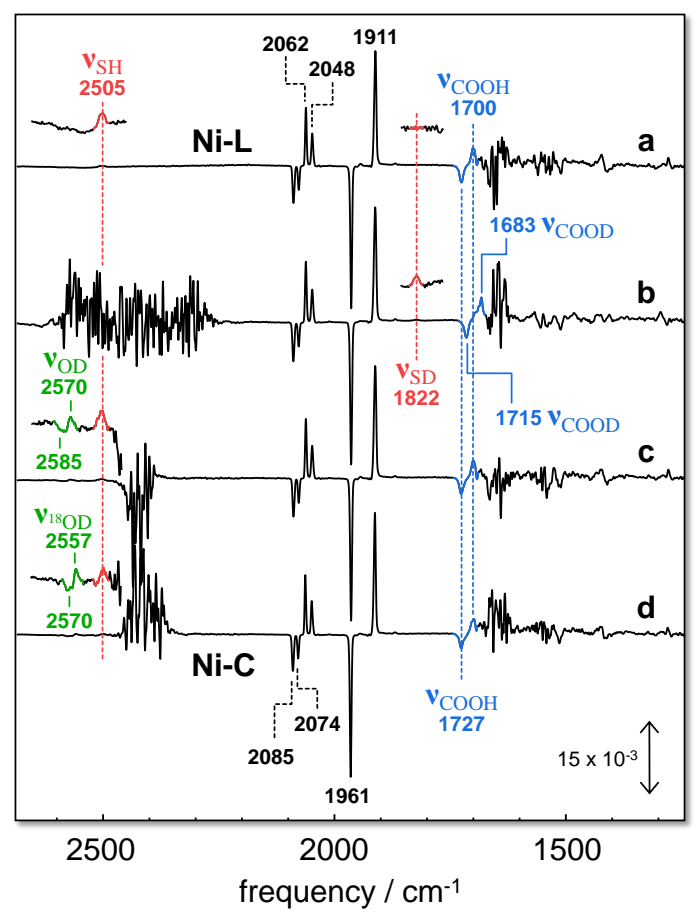

Figure 4 - FTIR difference spectra of the Ni-C $\rightarrow$ Ni-L transition. The data shows the difference between the spectra after and before light irradiation at $138 \mathrm{~K}$ and pH/D 7.0. Conditions: (a) $\mathrm{H}_{2} / \mathrm{H}_{2} \mathrm{O}$. (b) $\mathrm{D}_{2} / \mathrm{D}_{2} \mathrm{O}$. (c) $\mathrm{D}_{2} / \mathrm{H}_{2} \mathrm{O}$. (d) $\mathrm{D}_{2} / \mathrm{H}_{2}{ }^{18} \mathrm{O}$. Magnified spectra $(\times 10)$ in the $1765-1855$ and 2460-2655 $\mathrm{cm}^{-1}$ regions are also shown. The intensities of the spectra were normalized according to the intensities of the $v_{\mathrm{CO}}$ bands in spectrum (a). Legend: $v_{\mathrm{CO} / \mathrm{CN}}$ (black), $v_{\mathrm{COOH} / \mathrm{D}}$ (blue), $v_{\mathrm{SH} / \mathrm{D}}$ (red), $v_{\mathrm{OD}}$ and $v_{18 \mathrm{OD}}$ (green). Copyright 2019 Wiley-VCH.

Positive and negative $\mathrm{C}=\mathrm{O}$ stretching frequencies of $\mathbf{N i}-\mathbf{L}$ and $\mathbf{N i}-\mathbf{C}$ were observed at 1700 and $1727 \mathrm{~cm}^{-1}$, respectively, and found to be shifted to lower frequencies of 1683 and $1715 \mathrm{~cm}^{-1}$ in the deuterated sample (Figure 4, spectra a/b). ${ }^{7}$ These bands were assigned to E34 (Figure 1B). The $\mathrm{C}=\mathrm{O}$ stretching frequencies of carboxylic groups $\left(v_{\mathrm{COOH}}\right)$ under different environments have been estimated by combined theoretical and experimental studies. ${ }^{22}$ Here, lower frequencies suggest stronger hydrogen bonding, i.e. shorter distances and/or multiple partners. For Ni-C and Ni-L, $v_{\mathrm{COOH}}$ were observed at 1727 and $1700 \mathrm{~cm}^{-1}$, respectively, indicating that the E34 forms two 
hydrogen bonds in Ni-L (through the $\mathrm{OH}$ hydrogen and the $\mathrm{C}=\mathrm{O}$ oxygen of the $\mathrm{COOH}$ side chain) and a single hydrogen bond in Ni-C (through the $\mathrm{OH}$ hydrogen). As Ni-SIa shows $v_{\mathrm{COOH}}$ similar to Ni-C, E34 apparently exhibits a single hydrogen bond in $\mathbf{N i - S I} \mathbf{a}_{\mathbf{a}}$ as well. ${ }^{7}$

In the Ni-C $\rightarrow$ Ni-L difference spectrum of $\mathrm{D}_{2} / \mathrm{H}_{2} \mathrm{O}$-prepared $D v \mathrm{MF}[\mathrm{NiFe}]$-hydrogenase, an additional feature at $2570 \mathrm{~cm}^{-1}$ and $2585 \mathrm{~cm}^{-1}$ was observed (Figure 4, spectrum c). ${ }^{7}$ These bands shifted to lower frequencies of 2557 and $2570 \mathrm{~cm}^{-1}$, respectively, for the enzyme prepared in $\mathrm{D}_{2} / \mathrm{H}_{2}{ }^{18} \mathrm{O}$ (Figure 4, spectrum d). The observed isotope shifts $\left(\sim 14 \mathrm{~cm}^{-1}\right)$ were in good agreement with the increase in mass from ${ }^{16} \mathrm{O}$ to ${ }^{18} \mathrm{O}$ and facilitates assignment to a 'dangling water'. ${ }^{22}$ Such a water molecule may exists near the $\mathrm{Ni}-\mathrm{Fe}$ site, changing its orientation by realignment of the hydrogen-bonding network around C546 and E34 upon conversion of Ni-C to Ni-L.

\subsection{Understanding [NiFe]-hydrogenase catalysis}

Our spectroscopic results and the high-resolution crystal Ni-R structure of $D v \mathrm{MF}[\mathrm{NiFe}]-$ hydrogenase strongly indicate that the terminal, nickel-coordinated cysteine C546 is the primary proton donor/acceptor. ${ }^{7,9}$ Further, we found that the gradual realignment of the hydrogen-bonded network between C546, E34, A548, and T18 is essential for the efficient PT among Ni-C, Ni-L, and Ni-SI $\mathbf{a}$ in the catalytic cycle of $[\mathrm{NiFe}]$-hydrogenase (Figure $\mathbf{1 C}$ ). ${ }^{7,9}$ We propose that the catalytic reaction proceeds as follows:

In the first step, $\mathrm{H}_{2}$ is cleaved heterolytically (Eq. 1). This leads to the transition of the oxidized Ni-SI a to the fully-reduced Ni-R that is characterized by a $\mu \mathrm{H}^{-}$ligand at the $\mathrm{Ni}-\mathrm{Fe}$ site and a protonated C546-SH as the primary proton acceptor for the heterolytic cleavage of $\mathrm{H}_{2}$ (Figure 5). ${ }^{9}$ According to crystallographic analyses, E34-COOH and threonine T18 form a low-barrier hydrogen bond in Ni-R of $D v \mathrm{MF}[\mathrm{NiFe}]$-hydrogenase (Figure 5). ${ }^{9}$ The bond lengths between the 
$\mathrm{C}$ atom and two $\mathrm{O}$ atoms of the E34 side chain are 1.29 and $1.22 \AA$ and one of the E34 O atoms sits $2.58 \AA$ away from the $\mathrm{O}$ atom of the T18 side chain in Ni-R (Figure 1B), suggesting the involvement of these residues in the PT pathway. It is reasonable to assume that E34-COOH is additionally hydrogen-bonded to A548-NH in Ni-R. ${ }^{9}$ In the second step, $\mathbf{N i - C}$ is produced by oneelectron oxidation of Ni-R (Figure 5). ${ }^{7}$ Ni-C is also characterized by a $\mu \mathrm{H}^{-}$ligand ${ }^{35}$ but deprotonated at $\mathrm{C} 546$ and forms a single hydrogen bond to E34-COOH. ${ }^{7}$ The proton formerly bound to C546 may transfer to the nearby E34 during the conversion of Ni-R to Ni-C and the E34$\mathrm{COOH}$ is hydrogen-bonded to $\mathrm{C} 546$ in Ni-C. In the third step, C546-SH is restored by oxidation of the $\mu \mathrm{H}^{-}$at the Ni-Fe site of Ni-C, resulting in formation of Ni-L (Figure 5). ${ }^{35}$ Reprotonation of C546 in Ni-L has been demonstrated by the direct observation of the SH stretching frequency at $2505 \mathrm{~cm}^{-1}$ (Figure 4, spectrum a). ${ }^{7}$ The detected down-shift of the carboxylic $\mathrm{C}=\mathrm{O}$ stretching frequency is well compatible with E34 forming hydrogen bonds to both T18-OH and A548-NH. In the fourth step, one-electron oxidation of Ni-L restores Ni-SIa, accompanied with the release of a proton from C546-SH, and the formation of a hydrogen bond between E34-COOH and C546$\mathrm{S}^{-}$. Note the similar PT mechanism between the first and third steps as well as between the second and fourth steps. 


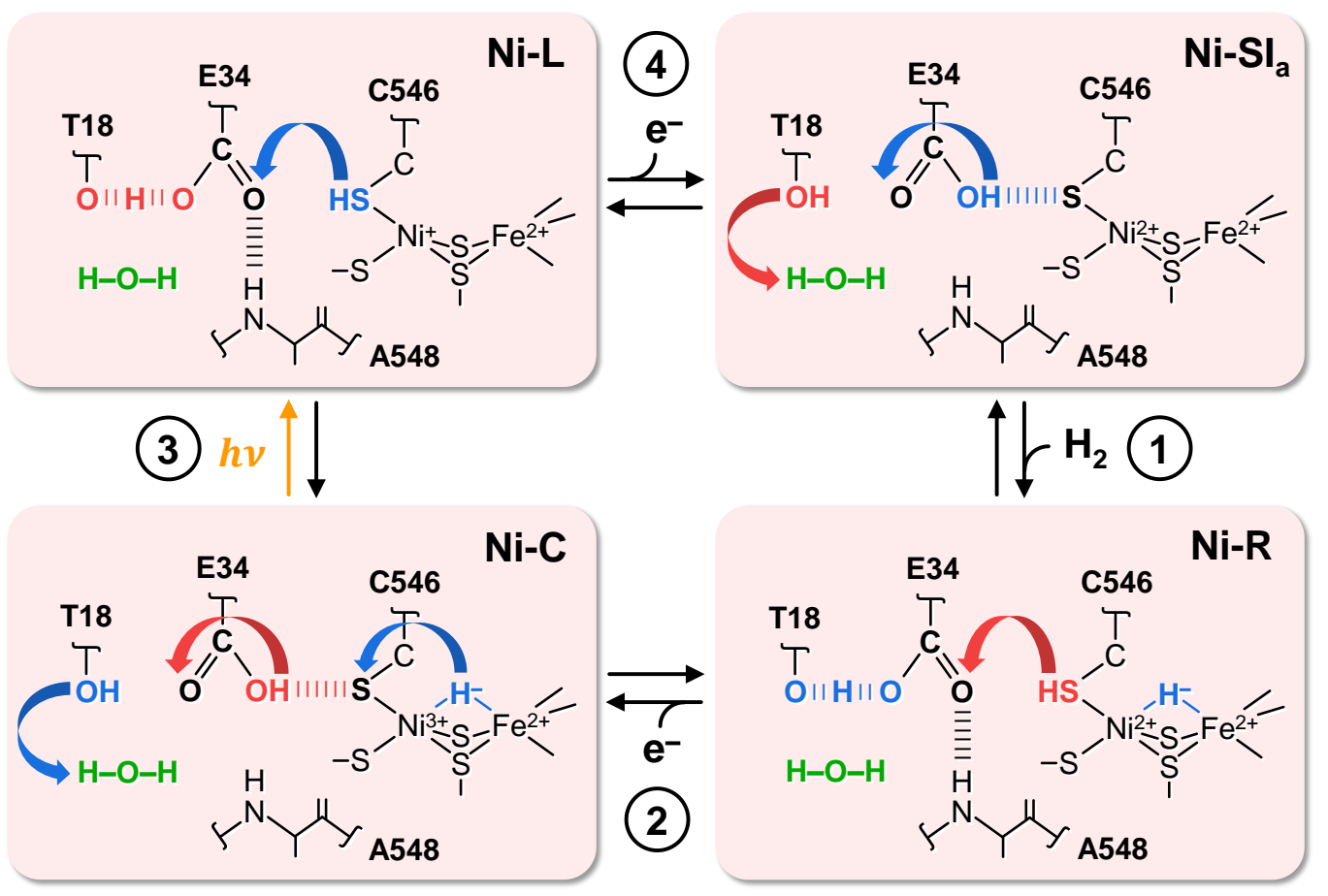

Figure 5 - Proposed proton transfer mechanism of [NiFe]-hydrogenase. (1) Upon binding to Ni-SI,$H_{2}$ is cleaved heterolytically and Ni-R is formed. A low-barrier hydrogen bond is found between E34 and T18 (vertical dashes). (2) The oxidative formation of Ni-C is accompanied by PT to T18 and E34. Moreover, FTIR spectroscopy identified hydrogen-bonding changes involving a 'dangling water'. (3) Upon conversion into Ni-L, the $\mu \mathrm{H}^{-}$ligand is lost to re-protonate C546. (4) The oxidative formation of Ni-SI $\mathbf{I}_{\mathbf{a}}$ is accompanied by PT to T18 and E34.

Several well-conserved water molecules are located near E34 and T18 in the crystal structure of $D v \mathrm{MF}[\mathrm{NiFe}]-$ hydrogenase. ${ }^{9}$ As discussed above, the FTIR data in Figure 4 (spectrum c) strongly suggest that a 'dangling water' near the Ni-Fe site may play an integral part in the PT pathway. ${ }^{7}$ A proton may transfer easily from an amino acid (e.g., T18) to the 'dangling water' during the catalytic reaction (Figure 5). There are well conserved amino-acid residues (E16, H36, D28, and $\mathrm{R} 38$ in $D v \mathrm{MF}$ sequence) and several water molecules in similar positions in [NiFe]-hydrogenase, indicating their possible involvement in the PT pathway. ${ }^{9}$ Additionally, the conversion of Ni-L 
into Ni-SI (step four) was observed only when the proximal [4Fe-4S] cluster was oxidized; thus, the $[4 \mathrm{Fe}-4 \mathrm{~S}]$ cluster may function as a gatekeeper for PCET between the Ni-Fe site and external redox partner. ${ }^{24}$

\subsection{Alternative proton transfer pathways}

An alternative PT pathway via the conserved arginine $\mathrm{R} 509$ (R479 in $D v \mathrm{MF}$, compare Figure 1B) has been proposed in the $\mathrm{O}_{2}$-tolerant $[\mathrm{NiFe}]$-hydrogenase from Escherichia coli $($ Ec $) .{ }^{36}$ This residue was suggested to function together with the active site as a frustrated Lewis pair to polarize and heterolytically cleave $\mathrm{H}_{2}$. The positively charged guanidium group of the arginine side chain may act as counterion to $\mu \mathrm{H}^{-}$in $\mathbf{N i - R}$ and $\mathbf{N i}-\mathbf{C}$, and this interaction is essential for the catalytic activity of $[\mathrm{NiFe}]$-hydrogenase. ${ }^{29}$ On the contrary, $\mathrm{Yu}$ et al. reported a terminal thiol-dominated H/D exchange between $\mathrm{H}_{2}$ and deuterated solvents in a diiron model complex. ${ }^{33}$ The strong acidic character of the terminal thiol facilitated fast proton exchange, clearly supporting the 'thiolhydride'-based mechanism for heterolytic cleavage of $\mathrm{H}_{2}$ in $[\mathrm{NiFe}]$-hydrogenase..$^{9,29}$

Evans et al. reported that the catalytic cycle of the E28Q variant of the $\mathrm{O}_{2}$-tolerant $E c$ [NiFe]hydrogenase was dominated by the reduced Ni-R and Ni-C, concluding that E28 (equivalent E34) is essential for the process occurring after formation of Ni-C. ${ }^{30}$ However, an additional PT pathway may be necessary for the transition of Ni-R to Ni-C in the E28Q variant. For example, an alternative 'histidine' pathway, connecting the $\mathrm{Ni}-\mathrm{Fe}$ site and the proximal [4Fe-3S] cluster, has been proposed in the $\mathrm{O}_{2}$-tolerant $[\mathrm{NiFe}]$-hydrogenase from Cupriavidus necator (formerly Ralstonia eutropha). ${ }^{37,38}$ Further studies are necessary to elucidate the comprehensive PT mechanism for the conversion of Ni-R to Ni-C. 


\section{Proton transfer in [FeFe]-hydrogenase}

\subsection{Light sensitivity of the $\mathrm{Fe}-\mathrm{Fe}$ active site}

Both parts of the $\mathrm{H}$-cluster, the $\mathrm{Fe}-\mathrm{Fe}$ site and the $[4 \mathrm{Fe}-4 \mathrm{~S}]$ cluster, react to UV/vis irradiation. For example, several studies have shown that the active-ready, oxidized Hox state converts into the CO-inhibited, oxidized Hox-CO state upon illumination. ${ }^{39-41}$ This reaction is caused by the sensitivity of metal carbonyl complexes to visible light. ${ }^{42-44}$ The conversion of Hox into Hox-CO is independent of $\mathrm{pH}$ and no significant changes in the carboxylic regime were detected by FTIR difference spectroscopy. ${ }^{8}$

Illuminating oxidized [FeFe]-hydrogenase with high intensity visible light under cryogenic conditions, resonance Raman spectroscopy revealed a one-electron reduction of the [4Fe-4S] cluster (Hox $\rightarrow$ Hred $\left.^{\prime}\right){ }^{45}$ Under ambient conditions, this redox conversion shows a clear dependence on $\mathrm{pH}$ and has been explained by a concerted protonation of a cysteine residue that coordinates to the $\left[4 \mathrm{Fe}-4 \mathrm{~S}\right.$ ] cluster (most likely C499, compare Figure $2 \mathbf{B}$ ). ${ }^{46,47}$ Notably, no significant changes in the carboxylic regime were detected by FTIR difference spectroscopy for the conversion of Hox into Hred ${ }^{\prime}{ }^{8}$ This is in agreement with PCET as protons are likely to proceed via a chain of 'conserved' water molecules (W2 in Figure 2B) that connect the [4Fe-4S] cluster to the protein surface. ${ }^{47}$ The W2 trajectory may have regulatory functions and must not be described as an 'alternative' PT pathway (Chapter 3.4). 


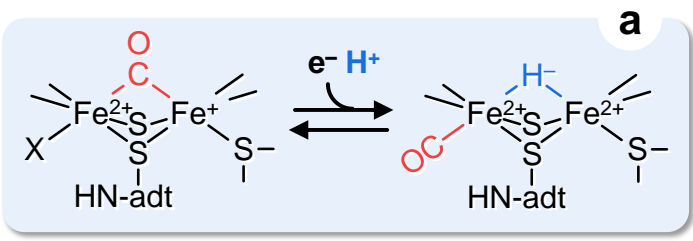

Hox Hred

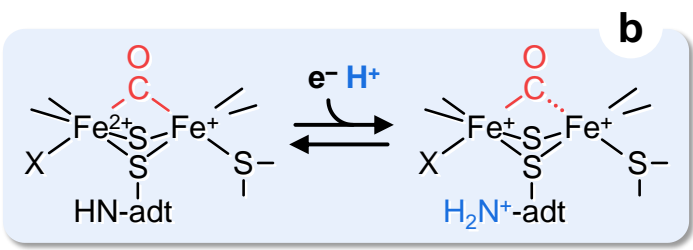

Hox $\mathrm{HredH}^{+}$

Figure 6 - Reduction and protonation of the Fe-Fe site. The two proposed models for the geometry of the reduced $\mathrm{Fe}-\mathrm{Fe}$ site. In model a, PCET leads to formation of a $\mathrm{Fe}-\mathrm{Fe}$ bridging hydride $\left(\mu \mathrm{H}^{-}\right)$and an apical CO at the distal iron ion instead of an open coordination site (' $\mathrm{X}$ '). In model $b$, PCET leads to protonation of the adt ligand $\left({ }^{+} \mathrm{NH}_{2}\right)$ and a weakening of the $\mu \mathrm{CO}$ ligand (dashed line). This geometry, referred to as $\mathbf{H r e d \mathbf { H } ^ { + }}$, may represent an intermediate in the $\mathbf{H o x} \rightarrow$ Hred conversion. Note: as electrons enter the H-cluster via the [4Fe-4S] cluster, an Hred'-like intermediate might be involved in the conversion as well (not shown).

Illuminating $\mathrm{H}_{2}$-reduced [FeFe]-hydrogenase with high intensity visible light under cryogenic conditions, a conversion of Hred and Hsred into H-cluster states with a terminal hydride similar to Hhyd has been noted. ${ }^{48}$ The $\mathrm{pH}$ dependence or the carboxylic IR difference signature has not been evaluated, neither is the molecular mechanism of the conversion understood. ${ }^{17}$ As the redox state of the [4Fe-4S] cluster differs in Hred and Hsred (Figure 2C), iron-sulfur photochemistry can be ruled out. Alternatively, it is tempting to explain the conversion to the presence of a photolabile $\mathrm{Fe}-\mathrm{Fe}$ bridging hydride ligand $\left(\mu \mathrm{H}^{-}\right)$in Hred and Hsred (Figure 6, model a), reminiscent of the Ni-C $\rightarrow$ Ni-L transition discussed in Chapter 2.2. Under ambient conditions, the IR signature of Hred and Hsred is in good agreement with a $\mu \mathrm{H}^{-}$geometry ${ }^{3}$ and the formation 
of a $\mu \mathrm{H}^{-}$ligand would explain the $\mathrm{pH}$-dependent midpoint potentials for the $\mathbf{H o x} \rightarrow$ Hred redox transition. ${ }^{49,50}$ However, several authors demonstrated that Hred and Hsred maintain a 'semibridging' or fully-bridged CO ligand at cryogenic temperatures, ${ }^{51,52}$ which would rule out the possibility of a $\mu \mathrm{H}^{-}$ligand (Figure 6, model b). To explain the $\mathrm{pH}$ dependence, a protonation of the aminodithiolate (adt) ligand has been proposed. ${ }^{49}$ We assume that the so-called $\mathbf{H r e d H}^{+}$state may represent an intermediate between Hox and Hred, kinetically trapped under cryogenic conditions not unlike Ni-L as an intermediate between Ni-C and Ni-SIa (Chaper 2.2). The influence of temperature and whether $\mathbf{H r e d}$ and $\mathbf{H r e d \mathbf { H } ^ { + }}$ really originate from different $\mathrm{H}$-cluster states is yet to decipher. ${ }^{17}$

\subsection{Proton transfer during the catalytic cycle}

In variance to Hred', there is no way to trigger the accumulation of Hred over Hox 'naturally' by visible light; however, numerous applications of redox dyes have been reported. ${ }^{53-55}$ Among these, 5' - -arboxy eosin $\mathrm{Y}$ in combination with EDTA as a sacrificial electron donor ${ }^{53}$ was found to facilitate an efficient photoreduction of the [FeFe]-hydrogenase from Chlamydomonas reinhardtii (CrHydA1) when illuminated at $505 \mathrm{~nm}$ under ambient conditions. ${ }^{8}$ Although Hred may represent an 'unready' H-cluster state (Chapter 3.3), its accumulation can be used to address changes in protonation and hydrogen-bonding in the catalytic PT pathway of [FeFe]-hydrogenase.

The FTIR difference spectrum in

Figure 7A depicts the conversion of Hox (negative bands) into Hred (positive bands). Less than $10 \%$ of other $\mathrm{H}$-cluster states were detected. In comparison to the $D v \mathrm{MF}$ [NiFe]-hydrogenase

(Figure 4), no difference bands were observed in the frequency regime of 'dangling water' (3800 $-3600 \mathrm{~cm}^{-1}$, not shown) or thioles ( $v_{\mathrm{SH}}$, inset 1$)$, which makes changes in protonation or hydrogen- 
bonding involving individual water molecules or cysteine residues highly improbable. ${ }^{8}$ In particular, the lack of SH difference signals is in conflict with a protonated adt ligand interacting with a cysteine (i.e., C299 in $C p \mathrm{I})$, arguing in favor of $\mathbf{H r e d}$ rather than $\mathbf{H r e d H}^{+}($Figure 6). This assignment is further supported by the lack of a $\mu \mathrm{CO}$ band, which is characteristic for $\mathbf{H r e d H}^{+}{ }^{51,52}$ The frequency regime $<1750 \mathrm{~cm}^{-1}$ (inset 2) was found to be considerably more complex than in [NiFe]-hydrogenase.

Figure 7B depicts the Hred - Hox difference spectrum in hydrated and deuterated sample. Here, two negative and two positive bands suggest hydrogen-bonding changes involving carboxylic side chains (blue labels), which is supported by a shift to lower frequencies in the deuterated sample. The negative band at $1681 \mathrm{~cm}^{-1}$ was found to shift more drastically (magenta traces), reminiscent of the large H/D isotope effect observed with guanidium hydrochloride, which facilitates assignment to an arginine residue. 

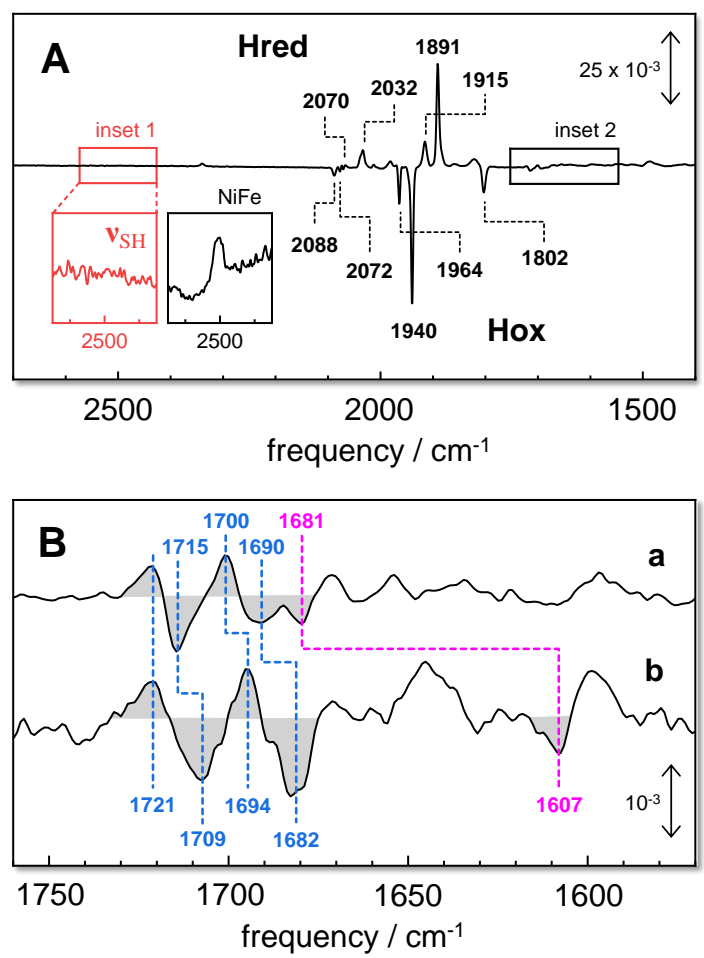

Figure 7 - FTIR difference spectra of the Hox to Hred transition. (A) FTIR difference spectrum for the accumulation of Hred over Hox as identified via the $\mathrm{CO} / \mathrm{CN}^{-}$bands of the $\mathrm{H}$ cluster (black labels). No significant changes were observed in the $\mathrm{OH}$ regime (not shown) and $\mathrm{SH}$ regime (inset 1). For comparison, the $\mathrm{SH}$ difference signal from Figure $4 \mathrm{~A}$ is depicted (NiFe, scaled by 1.5 to match the $\mathrm{CO}$ absorbance of cofactors). (B) Close-up of inset 2 in panel (A) for the same experiment on (a) hydrated and (b) deuterated [FeFe]-hydrogenase. Legend: $v_{\mathrm{CO} / \mathrm{CN}}$ (black), $v_{\mathrm{COOH}}$ (blue), and arginine (magenta).

Several amino acid variants of $\mathrm{CrHydA} 1$ were generated and crystallized to facilitate an experimental assignment of the FTIR difference spectra. ${ }^{8,16}$ For example, the lack of the arginine side chain in CrHydA1-R148A (eq. R286 in the [FeFe]-hydrogenase from Clostridium 
pasteurianum $C$ I) led to a disappearance of the band at $1681 \mathrm{~cm}^{-1}$ in $\mathbf{H o x}$, which is in excellent agreement with the H/D effect (

Figure 7B) and suggests deprotonation of R148 in the formation of Hred. Analyzing the E144D variant (eq. R282 in $C P \mathrm{I}$ ), a pronounced up-shift of the band at $1721 \mathrm{~cm}^{-1}$ was observed in Hred that can be explained by the lack of a hydrogen-bonding contact with R148 as suggested by crystallographic analyses before. ${ }^{16}$ Any variation of E141 (eq. R279 in $C p \mathrm{I}$ ) impeded accumulation of Hred over Hox. As none of the 'PT conservative' variants affected the $1715 \mathrm{~cm}^{-1} / 1700 \mathrm{~cm}^{-1}$ difference signal, we assigned this feature to E141 and concluded an increase in hydrogen-bonding strength in Hred compared to Hox.

The spectroscopic analysis of the catalytic hydrogen-bonding network in [FeFe]-hydrogenase identified subtle differences between the oxidized and reduced enzyme. ${ }^{8}$ Figure 8 shows our model of the 'discontinued' PT that is characterized by the lack of hydrogen-bonding interactions between S319 and E279 in Hox (panel a, note the cleft). Upon one-electron reduction of the diiron site, a proton is subtracted from E279 and binds to the H-cluster, forming the transient $\mathbf{H r e d H}^{+}$ state (panel b). Then, re-protonation via $\mathrm{R} 286^{+}$triggers the changes in the hydrogen-bonding network as shown in panel c. Instead of being involved in a hydrogen-bonding trans complex with a water molecule, E279 connects with S319 whereas E282 loses the hydrogen bond to the now deprotonated R286. We presume that re-protonation of R286 via the bulk solvent in Hred is precluded by the orientation of E279 and electrostatic repulsion. 


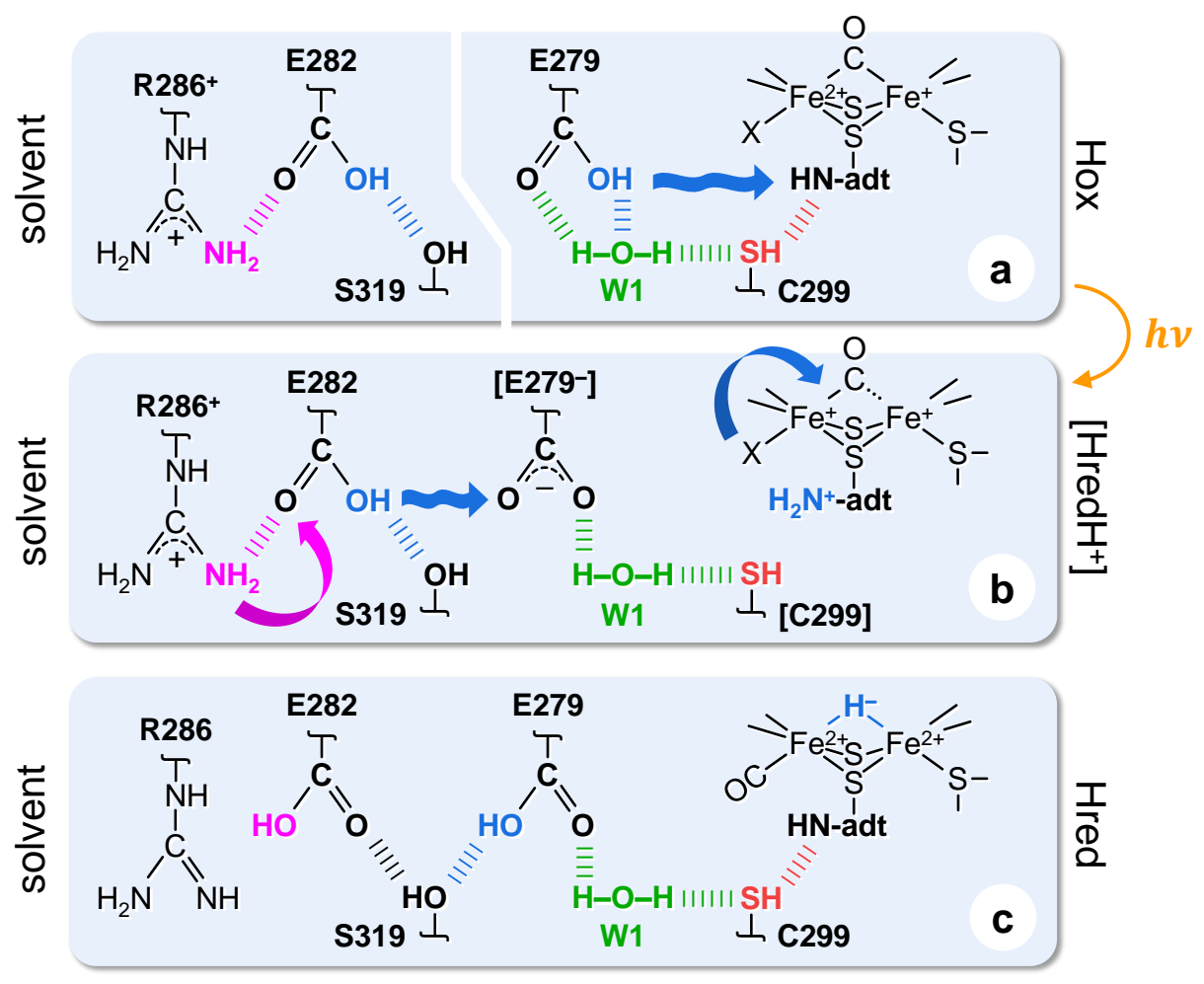

Figure 8 - Proposed proton transfer mechanism of [FeFe]-hydrogenase. Infrared data suggest hydrogen-bonding contacts between $\mathrm{R}^{286^{+}}$, E282, and S319 in the Hox state (CpI numbering, panel a). Crystallographic data allows concluding hydrogen-bonding between E279, W1, C299, and the adt ligand of the $\mathrm{H}$-cluster. Panel $\mathrm{b}$ shows a potential intermediate, characterized by deprotonation of E141 and protonation of the reduced H-cluster $\left(\mathbf{H r e d H}^{+}\right)$. The later relaxes towards the Hred state (panel c). Moreover, the E279/W1 complex dissolves in favor of hydrogen bonding between E279, S319, and E282, which facilitates continuous PT.

In conclusion, the model of 'discontinued' PT as detailed in Figure 8 provides a reasonable explanation how $[\mathrm{FeFe}]$-hydrogenase distinguishes proton influx $\left(\mathrm{H}_{2}\right.$ release $)$ from proton efflux ( $\mathrm{H}_{2}$ oxidation): in $\mathrm{H}_{2}$ release direction, $\mathrm{PT}$ is driven by an increase of basicitiy of the $\mathrm{H}$-cluster, i.e. upon reduction, and the transient subtraction of a proton from E141. In $\mathrm{H}_{2}$ oxidation direction, 
protons can leave the active site niche freely, i.e. triggered upon oxidation of the H-cluster, because the hydrogen-bonding environment allows for continuous PT.

\subsection{Understanding [FeFe]-hydrogenase catalysis}

Proton transfer determines the catalytic performance of [FeFe]-hydrogenase in multiple ways. Primarily, protons are educts in the $\mathrm{H}_{2}$ release reaction and products of the $\mathrm{H}_{2}$ oxidation reaction (Eq. 1) but the relation between [FeFe]-hydrogenase activity and proton concentration is arguably more complicated than this. For example, gas chromatographic analyses of solution assays show an increase of $\mathrm{H}_{2}$ evolution activity going from alkaline to neutral $\mathrm{pHs}$; however, the rate drops when the $\mathrm{pH}$ is lowered any further. ${ }^{56}$ Such assays typically rely on dithionite as a sacrificial donor, which might explain the $\mathrm{pH}$ dependence. To this end, Ruth et al. reported a set-up that combines electrochemical reduction and chromatographic gas analysis and observed that the catalytic activity of $[\mathrm{FeFe}]$-hydrogenase peaked at $\mathrm{pH} 6$, independent of dithionite. ${ }^{57}$

In a recent study, we addressed the influence of $\mathrm{pH}$ on the accumulation of reduced $\mathrm{H}$-cluster states under turnover conditions. ${ }^{50}$ We noted a clear trend for Hred to dominate at $\mathrm{pH}<7$ and Hred' to dominate at $\mathrm{pH}>7$, confirming former observations. ${ }^{47}$ This can explain the bell-shaped activity distribution as a function of $\mathrm{pH}$ : The preference for Hred under proton-rich conditions might indicate that the $\mathrm{H}$-cluster forms an unready, $\mathrm{H}_{2}$-inhibited geometry ${ }^{58}$ upon PCET to the $\mathrm{Fe}-\mathrm{Fe}$ active site, e.g. controlled by the low $p \mathrm{~K}_{\mathrm{a}}$ of the glutamic acid residues in the PT pathway (Figure 8). ${ }^{8}$ The water chain that connects the $[4 \mathrm{Fe}-4 \mathrm{~S}]$ cluster to the protein surface provides no such selectivity. Thus, Hred' is the main one-electron reduced H-cluster state under proton-poor conditions. ${ }^{50}$ Following the model devised in ref. 3 , site-selective protonation by PCET to the [4Fe4S] cluster and $\mathrm{Fe}-\mathrm{Fe}$ site allows [FeFe]-hydrogenase to switch between active-ready and unready $\mathrm{H}$-cluster geometries, e.g. in the context of $\mathrm{H}_{2}$ sensing. ${ }^{59,60}$ 


\subsection{Alternative proton transfer pathways}

Computational studies suggested three different PT pathways. ${ }^{20,21}$ Pathway 1 resembles the trajectory discussed above (Chapter 3.2). Pathway 2 shares the cysteine residue with pathway 1 but branches at the water cluster. It includes several other water molecules, a serine, and a lysine residue near the protein surface. Pathway 3 is independent from pathway 1 and 2: originally, it was proposed by Juan Fontecilla-Camps et al. assuming a hydrogen bond between the distal $\mathrm{CN}^{-}$ligand and a conserved lysine residue. ${ }^{13}$ Pathway 3 includes two glutamic acid residues and several other water molecules. ${ }^{21}$ A fourth pathway was considered first by John W. Peters and co-workers. ${ }^{12}$ Here, a methionine residue near the adt ligand of the H-cluster may facilitate PT, as supported by site-direct mutagenesis and enzymology studies. ${ }^{61}$

While pathway 1 has been identified as the main catalytic PT trajectory, ${ }^{16}$ alternative pathways may regulate PT in phylogenetically distinct $[\mathrm{FeFe}]$-hydrogenases. ${ }^{17}$ Such systems are largely unchartered, although first studies have emerged. ${ }^{59,60}$ In the future, it will be exciting to investigate 'novel' [FeFe]-hydrogenases by FTIR difference spectroscopy to solve the puzzle that is catalytic PT.

\section{Proton Transfer in Bimetallic Hydrogenase}

[NiFe]-hydrogenase and [FeFe]-hydrogenase belong to the family of iron-sulfur enzymes but have evolved independently throughout evolution. ${ }^{1}$ Nevertheless, the active site cofactors show a number of similarities, e.g. geometry and electronic structure, ligation motives, and metal hydride 
chemistry. Bimetallic hydrogenases catalyze the same reaction (Eq. 1) and suffer from both CO and $\mathrm{O}_{2}$ inhibition/deactivation, albeit to a different extent. ${ }^{3,4}$ Moreover, convergent evolution shaped several conformities in the mechanism of PT. This includes a cysteine proximal to the active site cofactor, followed by a glutamic acid and a serine or threonine residue. ${ }^{7,8}$ In $[\mathrm{FeFe}]-$ hydrogenase, the involvement of a small water cluster is undisputed (Figure 8) whereas respective water entities in [NiFe]-hydrogenase remain to be identified (Figure 5).

The independent FTIR analyses from our laboratories indicate hydrogen-bonding changes of the glutamic acid residue(s) in the PT pathway but no protonation differences, at least under steadystate conditions. ${ }^{7,8}$ In $[\mathrm{FeFe}]$-hydrogenase, hydrogen-bonding changes influence the directionality of PT whereas no spectral differences were observed with the proximal cysteine residue. This is in marked contrast to $[\mathrm{NiFe}]$-hydrogenase. Here, the protonation differences of the proximal cysteine may be the reason why $[\mathrm{NiFe}]$-hydrogenase show a clear bias towards $\mathrm{H}_{2}$ oxidation. ${ }^{1}$ We propose that the proximal cysteine at the $\mathrm{Ni}-\mathrm{Fe}$ cofactor serves as proton loading site while the proximal cysteine close to the $\mathrm{Fe}-\mathrm{Fe}$ site functions as flexible proton relay. In conclusion, FTIR difference spectroscopy has been demonstrated to serve as a powerful tool detecting subtle structural changes in the PT pathway of $[\mathrm{NiFe}]-$ and $[\mathrm{FeFe}]-h y d r o g e n a s e s$, despite the lack of a dedicated chromophore. Combined with high-resolution crystal structures, a conclusive and molecular-detailed description of PT in bimetallic hydrogenases is achieved.

\section{Acknowledgements}

We are grateful to all co-workers and collaboration partners named in the cited references. This work was partially supported by the National Natural Science Foundation of China (21977125 (H.T.)) and Grants-in-Aid for Scientific Research from JSPS (Category B, No. JP18H02088 (S.H.) and 
Category C, No. JP18K05318 (H.T.)). Further, we received financial supported by the Deutsche Forschungsgemeinschaft through the priority program 1927 (grant agreement No. 1554/5-1 (S.T.S.)).

\section{References}

(1) Lubitz, W.; Ogata, H.; Rüdiger, O.; Reijerse, E. Hydrogenases. Chem. Rev. 2014, 114 (8), 4081-4148. https://doi.org/10.1021/cr4005814.

(2) Tai, H.; Higuchi, Y.; Hirota, S. Comprehensive Reaction Mechanisms at and near the NiFe Active Sites of [NiFe] Hydrogenases. Dalt. Trans. 2018, 47 (13), 4408-4423. https://doi.org/10.1039/c7dt04910b.

(3) Haumann, M.; Stripp, S. T. The Molecular Proceedings of Biological Hydrogen Turnover. Acc. Chem. Res. 2018, 51 (8), 1755-1763. https://doi.org/10.1021/acs.accounts.8b00109.

(4) Tai, H.; Hirota, S. Mechanism and Application of the Catalytic Reaction of [NiFe] Hydrogenase: Recent Developments. ChemBioChem 2020, 21 (11), 1573-1581. https://doi.org/10.1002/cbic.202000058.

(5) Wittkamp, F.; Senger, M.; Stripp, S. T.; Apfel, U.-P. [FeFe]-Hydrogenases: Recent Developments and Future Perspectives. Chem. Commun. 2018, 54 (47), 5934-5942. https://doi.org/10.1039/C8CC01275J.

(6) Schilter, D.; Camara, J. M.; Huynh, M. T.; Hammes-Schiffer, S.; Rauchfuss, T. B. Hydrogenase Enzymes and Their Synthetic Models: The Role of Metal Hydrides. Chem. Rev. 2016, 116 (15), 8693-8749. https://doi.org/10.1021/acs.chemrev.6b00180.

(7) Tai, H.; Nishikawa, K.; Higuchi, Y.; Mao, Z.-W.; Hirota, S. Cysteine SH and Glutamate COOH Contributions to [NiFe] Hydrogenase Proton Transfer Revealed by Highly Sensitive FT-IR Spectroscopy. Angew. Chemie Int. Ed. 2019, 58 (38), 13285-13290. 
https://doi.org/10.1002/anie.201904472.

(8) Senger, M.; Eichmann, V.; Laun, K.; Duan, J.; Wittkamp, F.; Knör, G.; Apfel, U.-P.; Happe, T.; Winkler, M.; Heberle, J.; Stripp, S. T.; Timo, S. How [FeFe]-Hydrogenase Facilitates Bidirectional Proton Transfer. J. Am. Chem. Soc. 2019, 141 (43), 17394-17403. https://doi.org/10.1021/jacs.9b09225.

(9) Ogata, H.; Nishikawa, K.; Lubitz, W. Hydrogens Detected by Subatomic Resolution Protein Crystallography in a [NiFe] Hydrogenase. Nature 2015, 520 (7548), 571-574. https://doi.org/10.1038/nature14110.

(10) Volbeda, A.; Charon, M. H.; Piras, C.; Hatchikian, E. C.; Frey, M.; Fontecilla-Camps, J. C. Crystal Structure of the Nickel-Iron Hydrogenase from Desulfovibrio Gigas. Nature 1995, 373 (6515), 580-587. https://doi.org/10.1038/373580a0.

(11) Ash, P. A.; Hidalgo, R.; Vincent, K. A. Proton Transfer in the Catalytic Cycle of [NiFe] Hydrogenases: Insight from Vibrational Spectroscopy. ACS Catal. 2017, 7 (4), 2471-2485. https://doi.org/10.1021/acscatal.6b03182.

(12) Peters, J. W.; Lanzilotta, W. N.; Lemon, B. J.; Seefeldt, L. C. X-Ray Crystal Structure of the Fe-Only Hydrogenase (CpI) from Clostridium Pasteurianum to 1.8 Angstrom Resolution. $\quad$ Science $\quad \mathbf{1 9 9 8}, \quad 282 \quad$ (5395), $\quad 1853-1858$. https://doi.org/10.1126/science.282.5395.1853.

(13) Nicolet, Y.; Piras, C.; Legrand, P.; Hatchikian, C. E.; Fontecilla-Camps, J. C. Desulfovibrio Desulfuricans Iron Hydrogenase: The Structure Shows Unusual Coordination to an Active Site Fe Binuclear Center. Structure 1999, 7 (1), 13-23. https://doi.org/10.1016/S09692126(99)80005-7.

(14) Silakov, A.; Wenk, B.; Reijerse, E.; Lubitz, W. 14N HYSCORE Investigation of the H- 
Cluster of [FeFe] Hydrogenase: Evidence for a Nitrogen in the Dithiol Bridge. Phys. Chem. Chem. Phys. 2009, 11 (31), 6553-6554. https://doi.org/10.1039/b913085n.

(15) Winkler, M.; Esselborn, J.; Happe, T. Molecular Basis of [FeFe]-Hydrogenase Function: An Insight into the Complex Interplay between Protein and Catalytic Cofactor. Biochim. Biophys. Acta 2013, 1827 (8-9), 974-985. https://doi.org/10.1016/j.bbabio.2013.03.004.

(16) Duan, J.; Senger, M.; Esselborn, J.; Engelbrecht, V.; Wittkamp, F.; Apfel, U.-P.; Hofmann, E.; Stripp, S. T.; Happe, T.; Winkler, M. Crystallographic and Spectroscopic Assignment of the Proton Transfer Pathway in [FeFe]-Hydrogenases. Nat. Commun. 2018, 9, 4726. https://doi.org/10.1038/s41467-018-07140-x.

(17) Land, H.; Senger, M.; Berggren, G.; Stripp, S. T. Current State of [FeFe]-Hydrogenase Research - Biodiversity and Spectroscopic Investigations. ACS Catal. 2020, 10, 7069-7086. https://doi.org/10.1021/acscatal.0c01614.

(18) Teixeira, V. H.; Soares, C. M.; Baptista, A. M. Proton Pathways in a [NiFe]-Hydrogenase: A Theoretical Study. Proteins Struct. Funct. Genet. 2007, 70 (3), 1010-1022. https://doi.org/10.1002/prot.21588.

(19) Galván, I. F.; Volbeda, A.; Fontecilla-Camps, J. C.; Field, M. J. A QM/MM Study of Proton Transport Pathways in a [NiFe] Hydrogenase. Proteins Struct. Funct. Genet. 2008, 73 (1), 195-203. https://doi.org/10.1002/prot.22045.

(20) Long, H.; King, P. W.; Chang, C. H. Proton Transport in Clostridium Pasteurianum [FeFe] Hydrogenase I: A Computational Study. J. Phys. Chem. B 2014, 118 (4), 890-900. https://doi.org/10.1021/jp408621r.

(21) Ginovska-Pangovska, B.; Ho, M.-H.; Linehan, J. C.; Cheng, Y.; Dupuis, M.; Raugei, S.; Shaw, W. J. Molecular Dynamics Study of the Proposed Proton Transport Pathways in 
[FeFe]-Hydrogenase. Biochim. Biophys. Acta 2014, 1837 (1), 131-138. https://doi.org/10.1016/j.bbabio.2013.08.004.

(22) Lorenz-Fonfria, V. A. Infrared Difference Spectroscopy of Proteins: From Bands to Bonds. Chem. Rev. 2020, 120 (7), 3466-3576. https://doi.org/10.1021/acs.chemrev.9b00449.

(23) Tai, H.; Xu, L.; Inoue, S.; Nishikawa, K.; Higuchi, Y.; Hirota, S. Photoactivation of the NiSIr State to the Ni-SIa State in [NiFe] Hydrogenase: FT-IR Study on the Light Reactivity of the Ready Ni-SIr State and as-Isolated Enzyme Revisited. Phys. Chem. Chem. Phys. 2016, 18 (32), 22025-22030. https://doi.org/10.1039/c6cp04628b.

(24) Tai, H.; Nishikawa, K.; Suzuki, M.; Higuchi, Y.; Hirota, S. Control of the Transition between Ni-C and Ni-SIastates by the Redox State of the Proximal Fe-S Cluster in the Catalytic Cycle of [NiFe] Hydrogenase. Angew. Chemie - Int. Ed. 2014, 53 (50), 1381713820. https://doi.org/10.1002/anie.201408552.

(25) Tai, H.; Xu, L.; Nishikawa, K.; Higuchi, Y.; Hirota, S. Equilibrium between Inactive Ready Ni-SIr and Active Ni-SIa States of [NiFe] Hydrogenase Studied by Utilizing Ni-SIr-to-NiSIa Photoactivation. Chem. Commun. 2017, 53 (75), 10444-10447. https://doi.org/10.1039/c7cc06061k.

(26) Bell, R. P. Recent Advances in the Study of Kinetic Hydrogen Isotope Effects. Chem. Soc. Rev. 1974, 3 (4), 513-544. https://doi.org/10.1039/CS9740300513.

(27) Dong, G.; Ryde, U. Protonation States of Intermediates in the Reaction Mechanism of [NiFe] Hydrogenase Studied by Computational Methods. J. Biol. Inorg. Chem. 2016, 21 (3), 383-394. https://doi.org/10.1007/s00775-016-1348-9.

(28) Dementin, S.; Burlat, B.; De Lacey, A. L.; Pardo, A.; Adryanczyk-Perrier, G.; Guigliarelli, B.; Fernandez, V. M.; Rousset, M. A Glutamate Is the Essential Proton Transfer Gate during 
the Catalytic Cycle of the [NiFe] Hydrogenase. J. Biol. Chem. 2004, 279 (11), 1050810513. https://doi.org/10.1074/jbc.M312716200.

(29) Greene, B. L.; Vansuch, G. E.; Wu, C. H.; Adams, M. W. W.; Dyer, R. B. Glutamate Gated Proton-Coupled Electron Transfer Activity of a [NiFe]-Hydrogenase. J. Am. Chem. Soc. 2016, 138 (39), 13013-13021. https://doi.org/10.1021/jacs.6b07789.

(30) Evans, R. M.; Ash, P. A.; Beaton, S. E.; Brooke, E. J.; Vincent, K. A.; Carr, S. B.; Armstrong, F. A. Mechanistic Exploitation of a Self-Repairing, Blocked Proton Transfer Pathway in an O2-Tolerant [NiFe]-Hydrogenase. J. Am. Chem. Soc. 2018, 140 (32), 1020810220. https://doi.org/10.1021/jacs.8b04798.

(31) Gebler, A.; Burgdorf, T.; De Lacey, A. L.; Rüdiger, O.; Martinez-Arias, A.; Lenz, O.; Friedrich, B. Impact of Alterations near the [NiFe] Active Site on the Function of the H2 Sensor from Ralstonia Eutropha. FEBS J. 2007, $274 \quad$ (1), 74-85. https://doi.org/10.1111/j.1742-4658.2006.05565.x.

(32) Weber, K.; Krämer, T.; Shafaat, H. S.; Weyhermüller, T.; Bill, E.; Van Gastel, M.; Neese, F.; Lubitz, W. A Functional [NiFe]-Hydrogenase Model Compound That Undergoes Biologically Relevant Reversible Thiolate Protonation. J. Am. Chem. Soc. 2012, 134 (51), 20745-20755. https://doi.org/10.1021/ja309563p.

(33) Yu, X.; Pang, M.; Zhang, S.; Hu, X.; Tung, C. H.; Wang, W. Terminal Thiolate-Dominated H/D Exchanges and H2 Release: Diiron Thiol-Hydride. J. Am. Chem. Soc. 2018, 140 (36), 11454-11463. https://doi.org/10.1021/jacs.8b06996.

(34) Tai, H.; Nishikawa, K.; Inoue, S.; Higuchi, Y.; Hirota, S. FT-IR Characterization of the Light-Induced Ni-L2 and Ni-L3 States of [NiFe] Hydrogenase from Desulfovibrio Vulgaris Miyazaki F. J. Phys. Chem. B 2015, $119 \quad$ (43), 13688-13674. 
https://doi.org/10.1021/acs.jpcb.5b03075.

(35) Brecht, M.; Van Gastel, M.; Buhrke, T.; Friedrich, B.; Lubitz, W. Direct Detection of a Hydrogen Ligand in the [NiFe] Center of the Regulatory H2-Sensing Hydrogenase from Ralstonia Eutropha in Its Reduced State by HYSCORE and ENDOR Spectroscopy. J. Am. Chem. Soc. 2003, 125 (43), 13075-13083. https://doi.org/10.1021/ja036624x.

(36) Evans, R. M.; Brooke, E. J.; Wehlin, S. A. M.; Nomerotskaia, E.; Sargent, F.; Carr, S. B.; Phillips, S. E. V.; Armstrong, F. A. Mechanism of Hydrogen Activation by [NiFe] Hydrogenases. Nat. Chem. Biol. 2016, $12 \quad$ (1), 46-50. https://doi.org/10.1038/nchembio.1976.

(37) Tombolelli, D.; Mroginski, M. A. Proton Transfer Pathways between Active Sites and Proximal Clusters in the Membrane-Bound [NiFe] Hydrogenase. J. Phys. Chem. B 2019, 123 (16), 3409-3420. https://doi.org/10.1021/acs.jpcb.9b00617.

(38) Frielingsdorf, S.; Fritsch, J.; Schmidt, A.; Hammer, M.; Löwenstein, J.; Siebert, E.; Pelmenschikov, V.; Jaenicke, T.; Kalms, J.; Rippers, Y.; Lendzian, F.; Zebger, I.; Teutloff, C.; Kaupp, M.; Bittl, R.; Hildebrandt, P.; Friedrich, B.; Lenz, O.; Scheerer, P. Reversible [4Fe-3S] Cluster Morphing in an O 2 -Tolerant [NiFe] Hydrogenase. Nat. Chem. Biol. 2014, 10 (5), 378-385. https://doi.org/10.1038/nchembio.1500.

(39) Lemon, B. J.; Peters, J. W. Photochemistry at the Active Site of the Carbon Monoxide Inhibited Form of the Iron-Only Hydrogenase (CpI). J. Am. Chem. Soc. 2000, 122 (15), 3793-3794. https://doi.org/10.1021/ja9943703.

(40) Bennett, B.; Lemon, B. J.; Peters, J. W. Reversible Carbon Monoxide Binding and Inhibition at the Active Site of the Fe-Only Hydrogenase. Biochemistry 2000, 39 (25), $7455-7460$. 
(41) Chen, Z.; Lemon, B. J.; Huang, S.; Swartz, D. J.; Peters, J. W.; Bagley, K. A. Infrared Studies of the CO-Inhibited Form of the Fe-Only Hydrogenase from Clostridium Pasteurianum I: Examination of Its Light Sensitivity at Cryogenic Temperatures. Biochemistry 2002, 41 (6), 2036-2043. https://doi.org/10.1021/bi011510o.

(42) Albracht, S. P. J.; Roseboom, W.; Hatchikian, E. C. The Active Site of the [FeFe]Hydrogenase from Desulfovibrio Desulfuricans. I. Light Sensitivity and Magnetic Hyperfine Interactions as Observed by Electron Paramagnetic Resonance. J. Biol. Inorg. Chem. 2006, 11 (1), 88-101. https://doi.org/10.1007/s00775-005-0039-8.

(43) Roseboom, W.; De Lacey, A. L.; Fernandez, V. M.; Hatchikian, E. C.; Albracht, S. P. J. The Active Site of the [FeFe]-Hydrogenase from Desulfovibrio Desulfuricans. II. Redox Properties, Light Sensitivity and CO-Ligand Exchange as Observed by Infrared Spectroscopy. J. Biol. Inorg. Chem. 2006, 11 (1), 102-118. https://doi.org/10.1007/s00775005-0040-2.

(44) Sensi, M.; Baffert, C.; Fradale, L.; Gauquelin, C.; Soucaille, P.; Meynial-Salles, I.; Bottin, H.; De Gioia, L.; Bruschi, M.; Fourmond, V.; Léger, C.; Bertini, L. Photoinhibition of FeFe Hydrogenase. $\quad$ ACS $\quad$ Catal. $\quad$ 2017, $\quad 7 \quad$ (10), https://doi.org/10.1021/acscatal.7b02252.

(45) Katz, S.; Noth, J.; Horch, M.; Shafaat, H. S.; Happe, T.; Hildebrandt, P.; Zebger, I. Vibrational Spectroscopy Reveals the Initial Steps of Biological Hydrogen Evolution. Chem. Sci. 2016, 7, 6746-6752. https://doi.org/10.1039/C6SC01098A.

(46) Senger, M.; Laun, K.; Wittkamp, F.; Duan, J.; Haumann, M.; Happe, T.; Winkler, M.; Apfel, U.-P.; Stripp, S. T. Proton-Coupled Reduction of the Catalytic [4Fe-4S] Cluster in [FeFe]Hydrogenases. Angew. Chemie Int. Ed. 2017, 56 (52), 16503-16506. 
https://doi.org/10.1002/anie.201709910.

(47) Senger, M.; Mebs, S.; Duan, J.; Shulenina, O.; Laun, K.; Kertess, L.; Wittkamp, F.; Apfel, U.-P.; Happe, T.; Winkler, M.; Haumann, M.; Stripp, S. T. Protonation/Reduction Dynamics at the $[4 \mathrm{Fe}-4 \mathrm{~S}]$ Cluster of the Hydrogen-Forming Cofactor in $[\mathrm{FeFe}]-$ Hydrogenases. Phys. Chem. Chem. Phys. 2018, 20 (5), 3128-3140. https://doi.org/10.1039/C7CP04757F.

(48) Lorent, C.; Katz, S.; Duan, J.; Julia Kulka, C.; Caserta, G.; Teutloff, C.; Yadav, S.; Apfel, U.-P.; Winkler, M.; Happe, T.; Horch, M.; Zebger, I. Shedding Light on Proton and Electron Dynamics in [FeFe] Hydrogenases. J. Am. Chem. Soc. 2020, 142 (12), 5493-5497. https://doi.org/10.1021/jacs.9b13075.

(49) Sommer, C.; Adamska-Venkatesh, A.; Pawlak, K.; Birrell, J. A.; Rüdiger, O.; Reijerse, E. J.; Lubitz, W. Proton Coupled Electronic Rearrangement within the H-Cluster as an Essential Step in the Catalytic Cycle of [FeFe] Hydrogenases. J. Am. Chem. Soc. 2017, 139 (4), 1440-1443. https://doi.org/10.1021/jacs.6b12636.

(50) Laun, K.; Baranova, I.; Duan, J.; Wittkamp, F.; Apfel, U.-P.; Happe, T.; Senger, M.; Stripp, S. T. Site-Selective Protonation of the Catalytic Cofactor in [FeFe]-Hydrogenase. ChemRxiv 2019. https://doi.org/https://doi.org/10.26434/chemrxiv.9970571.v2.

(51) Ratzloff, M. W.; Artz, J. H.; Mulder, D. W.; Collins, R. T.; Furtak, T. E.; King, P. W. COBridged H-Cluster Intermediates in the Catalytic Mechanism of [FeFe]-Hydrogenase CaI. J. Am. Chem. Soc. 2018, 140 (24), 7623-7628. https://doi.org/10.1021/jacs.8b03072.

(52) Birrell, J. A.; Pelmenschikov, V.; Mishra, N.; Wang, H.; Yoda, Y.; Rauchfuss, T. B.; Cramer, S. P.; Lubitz, W.; Debeer, S. Spectroscopic and Computational Evidence That [FeFe] Hydrogenases Operate Exclusively with CO-Bridged Intermediates Spectroscopic 
and Computational Evidence That [ FeFe ] Hydrogenases Operate Exclusively with COBridged. J. Am. Chem. Soc. 2020, 142 (1), 222-232. https://doi.org/10.1021/jacs.9b09745. Adam, D.; Bösche, L.; Castaneda-Losada, L.; Winkler, M.; Apfel, U.-P.; Happe, T. Sunlight-Dependent Hydrogen Production by Photosensitizer / Hydrogenase Systems. ChemSusChem 2017, 10 (5), 894-902. https://doi.org/10.1002/cssc.201601523.

(54) Greene, B. L.; Schut, G. J.; Adams, M. W. W.; Dyer, R. B. Pre-Steady-State Kinetics of Catalytic Intermediates of an [FeFe]-Hydrogenase. ACS Catal. 2017, 7, 2145-2150. https://doi.org/10.1021/acscatal.6b03276.

(55) Sanchez, M. L. K.; Sommer, C.; Reijerse, E.; Birrell, J. A.; Lubitz, W.; Dyer, R. B. Investigating the Kinetic Competency of CrHydA1 [FeFe] Hydrogenase Intermediate States via Time-Resolved Infrared Spectroscopy. J. Am. Chem. Soc. 2019, 141 (40), 16064-16070. https://doi.org/10.1021/jacs.9b08348.

(56) Happe, T.; Naber, J. D. Isolation, Characterization and N-terminal Amino Acid Sequence of Hydrogenase from the Green Alga Chlamydomonas Reinhardtii. Eur. J. Biochem. 1993, 214 (2), 475-481. https://doi.org/10.1111/j.1432-1033.1993.tb17944.x.

(57) Ruth, J. C.; Milton, R. D.; Gu, W.; Spormann, A. M. Enhanced Electrosynthetic Hydrogen Evolution by Hydrogenases Embedded in a Redox-Active Hydrogel. Chem. - A Eur. J. 2020, in press. https://doi.org/10.1002/chem.202000750.

(58) Duan, J.; Mebs, S.; Laun, K.; Wittkamp, F.; Heberle, J.; Hofmann, E.; Apfel, U.-P.; Winkler, M.; Senger, M.; Haumann, M.; Stripp, S. T. Geometry of the Catalytic Active Site in $[\mathrm{FeFe}]-H y d r o g e n a s e$ Is Determined by Hydrogen Bonding and Proton Transfer. ACS Catal. 2019, 9 (10), 9140-9149. https://doi.org/10.1021/acscatal.9b02203.

(59) Chongdar, N.; Birrell, J. A.; Pawlak, K.; Sommer, C.; Reijerse, E. J.; Rüdiger, O.; Lubitz, 
W.; Ogata, H. Unique Spectroscopic Properties of the H-Cluster in a Putative Sensory [FeFe] Hydrogenase. J. Am. Chem. Soc. 2018, 140 (3), 1057-1068. https://doi.org/10.1021/jacs.7b11287.

(60) Land, H.; Ceccaldi, P.; Mészáros, L. S.; Lorenzi, M.; Redman, H. J.; Senger, M.; Stripp, S. T.; Berggren, G. Discovery of Novel [FeFe]-Hydrogenases for Biocatalytic H2-Production. Chem. Sci. 2019, 10 (43), 9941-9948. https://doi.org/10.1039/c9sc03717a.

(61) Knörzer, P.; Silakov, A.; Foster, C. E.; Armstrong, F. A.; Lubitz, W.; Happe, T. Importance of the Protein Framework for Catalytic Activity of [FeFe]-Hydrogenases. J. Biol. Chem. 2012, 287 (2), 1489-1499. https://doi.org/10.1074/jbc.M111.305797. 